\title{
Chemical Modification of Nanocellulose in Wood Adhesive: Review
}

\author{
S. K. Vineeth*, Ravindra V. Gadhave, Pradeep T. Gadekar \\ Department of Polymer and Surface Engineering, Institute of Chemical Technology, Mumbai, India \\ Email: *vineetheskay@gmail.com
}

How to cite this paper: Vineeth, S.K., Gadhave, R.V. and Gadekar, P.T. (2019) Chemical Modification of Nanocellulose in Wood Adhesive: Review. Open Journal of Polymer Chemistry, 9, 86-99. https://doi.org/10.4236/ojpchem.2019.94008

Received: September 21, 2019

Accepted: October 29, 2019

Published: November 1, 2019

Copyright $\odot 2019$ by author(s) and Scientific Research Publishing Inc. This work is licensed under the Creative Commons Attribution International License (CC BY 4.0).

http://creativecommons.org/licenses/by/4.0/ (c) (i) Open Access

\begin{abstract}
Bio-based nanomaterial is more attractive, due to its abundance, eco-friendliness and sustainability, when compared to the non-renewable toxic petrochemicals used in the wood adhesive sector. Recent studies on the formaldehyde emission by petrochemical binders in wood adhesives have attracted scientists for the research in biomaterial-based binders. In this aspect nanocellulose (NC) is one such material which has reinforcing ability and has natural binding properties. Conventional wood adhesive uses petrochemical-based binders and additives. Inclusion of nanocellulose in wood adhesive could drastically reduce the dependency on non-renewable petroleum sources. Even though wood adhesive uses NC for improving mechanical properties of the adhesive, usage is restricted because of its inability to enhance tackiness and adhesion compared with petrochemicals. Availability of free hydroxyl groups and feasibility for modification can be a potential way for functionalization of this nanomaterial. To improve adhesion properties and to make nanocellulose act as a functional filler, the crosslinking approach can be a possible solution. Enhancement of thermal properties with improved thermal degradation, water barrier properties of crosslinked films and enhanced mechanical properties especially in crosslinked poly (vinyl alcohol) (PVA) matrix, which is one of the binders for wood adhesive discussed in this review paper proves the potential applicability of crosslinked NC. Hence by inclusion of NC in wood adhesive and crosslinking with the binder, both mechanical and performance properties are expected to enhance which will create a new world and possibilities for the bio-based eco-friendly wood adhesives. In this review paper, we have reviewed the crosslinking of nanocellulose to enhance the performance of wood adhesives.
\end{abstract}

\section{Keywords}

Nanocellulose, Biomaterial, Wood, Adhesive, Modification, Crosslinking 


\section{Introduction}

Wood adhesives have seen a lot of evolution in the point of application, performance properties, selection of base resin, distinct formulation and biomaterials as functional additives, and introduction to nanotechnology. Regardless of specific applications in the manufacturing of wood products, the requirement of a wood adhesive is its bondability. Type of adherent material, bond line geometry, and loading conditions affect the adhesive strength. Hence addition of fillers which could enhance bond strength has a huge potential. Concerns on environmental pollution by emission of volatile organic content by petrochemicals as adhesives and additives in wood adhesive and studies on toxicity of conventional formaldehyde-based adhesives, and the development for new materials are requisite. The cause of release of formaldehyde is mainly due to the unreacted formaldehyde and hydrolysis of formaldehyde-based adhesives under hot/humid conditions from the adhesive applied panels [1] [2]. This problem hence hinders in the usage of conventional formaldehyde-based adhesives concerning its non-ecofriendly aspect [3]. Studies on biopolymer-based wood adhesives have suggested an alternative to conventional adhesives and its potentiality to reduced formaldehyde emission [4] [5] [6]. Biomaterial based wood adhesive has the advantage renewability and reduced formaldehyde release [7]. In this context, biomaterials as both additives and adhesion promoters have a bright future in sustainable development [8]. Demand for bio-based adhesives and adhesion promoters, as an eco-friendly material, without compromising the performance properties of adhesives has led considerable attention in the scientific community.

Various biomaterials have been a subject to researchers in adhesive field; these include, starch [9] [10] [11] [12] [13], modified vegetable oils or lignin derivatives [14]-[20], soy protein [21] [22] [23] [24] [25], renewable rubber [26] [27] [28] [29], and cellulosic materials [30]-[39]. Cellulosic materials are a wide class of polysaccharide of glucosidic linkages. Commercial source of cellulose is soft and hardwood from higher plants. Cellulose is a long-chain, high molecular weight polysaccharide composed of repeat units of dimers or disaccharides of the anhydro-D-glucopyranoseunit (AGU), known as cellobiose $\beta$-1,4glycosidic linkage. It connects each anhydro-D glucopyranose unit, and every monomer is rotated $180^{\circ}$ concerning its neighboring unit [40]. The structure of cellulose is shown in Figure 1. Nanocellulose (NC) is isolated cellulosic materials with one

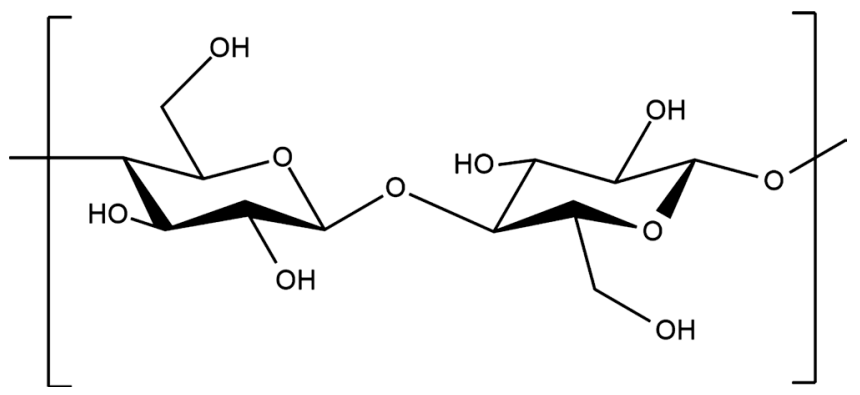

Figure 1. Structure of cellulose. 
dimension in the nanometer range [41]. They may be cellulose nanocrystals (NCC or CNC), nano fibrillated celluloses (CNF) and bacterial nanocellulose. Mechanical or chemical treatments are employed in extraction of nanocellulose [42] and compared to its bulk, nanocellulose shows unique properties [43]. Nanocellulose has its potentiality both as biomaterial and sustainable nanomaterials. The added advantage includes large abundance, cheap and economical to adhesive industry, easy to process and compatibility with various adhesive systems. Nanocellulose have high surface to volume ratio and primary hydroxyl groups which can be modified [44]. In wood adhesives, hence by addition of very small amount of nanocellulose, enhancement of properties is observed [45] [46] [47] [48].

To furthermore enhance the properties of biomaterials-based wood adhesives, the interphasial chemistry of biomaterial and binder resin should be improved. Various possibilities are exploited in enhancing properties of wood adhesives such as, silane modification of starch-based wood adhesives [49], esterification of starch for wood adhesives, addition of acrylic ester as co-monomer to starch [12] and crosslinking. Many studies on crosslinking of wide range of biomaterials for improvement in properties of wood adhesives have been reported [6], [49] [50] [51] [52]. Crosslinking is one of the promising techniques which could be carried for various biomaterial-based adhesive systems. Even though most of the studies on nanocellulose as a nano reinforcing agent in adhesives are investigated [53] [54], if functionalization could be made especially crosslinks then properties of nanocellulose based wood adhesives could be again enhanced.

This review paper discusses the modification of the bio-based material, nanocellulose for application in adhesives so to put a step forward to reduce the dependency on petroleum sources. Studies on nanocellulose as a reinforcing agent by enhancing adhesive performance are discussed initially. Crosslinkers for nanocellulose and property enhancements in Polyvinyl alcohol (PVA)-nanocellulose crosslinker nanocomposites are discussed since it can be helpful in establishing PVA-crosslinked nanocellulose based wood adhesives. The main focus of this review paper is on modification of nanocellulose by crosslinking and applicability in PVA based wood adhesive sector. This strategy will aim to increase the number and scale of biomaterial in adhesive applications.

\section{Modification of Wood Adhesives with Nanocellulose}

The potential use of nanocellulose in wood adhesive has been intensely studied because of its inherent binding properties [55], the reinforcing properties of this nanomaterial due to high surface to volume ratio [56], and enhancing the performance properties of the adhesive. For the optimization of mechanical and performance characteristics, the possibilities offered by adding filler or fibrous particles to alter the properties have attracted researchers. In general, physicochemical properties of the adhesives get affected by the addition of nanocellulose. Increase in the addition of nanocellulose causes an increase in viscosity and 
the solid content in the adhesive system. To replace Carcinogenic chemical adhesives, CNF as a reinforcement in wood flour (WF) board and binding effect of CNF in this system were investigated by Kojima et al. [57]. For the improvement of the mechanical board properties by urea-formaldehyde (UF) and melamine-urea-formaldehyde (MUF), a study on the addition of cellulose nanofibers (CNFs) in various concentrations as reinforcement was investigated by Veigel et al. [48]. Aqueous CNF suspension was mixed with UF and MUF adhesives. Fracture energy and fracture toughness enhanced on addition of CNF, and best results were at CNF content of $1 \mathrm{wt} \%$. Similar work on toughening UF adhesives, CNF was reinforced with the system [33]. To separate individual fibril, oxidation by (2,2,6,6-tetramethylpiperidin-1-yl)oxyl (TEMPO) followed by high-pressure homogenization were done on CNF. But UF bonds filled with untreated nanofibrils showed the highest fracture energy values. With $2 \% \mathrm{CNF}$, toughening effect up to $45 \%$ was observed. The work concluded that optimum content of $\mathrm{CNF}$ and its type are one factor influencing the properties of adhesive.

For the performance enhancement of tannin-based particleboards, CNF was reinforced [58]. Increase in viscosity on the addition of CNF was recorded, due to strong hydrogen bond network between CNF and with tannin molecules. Enhancement in the mechanical properties of the panels and improvement in internal bonding strength (IB) even with $2 \%$ of CNF, without affecting the water-resistance was observed in work. A similar work investigated on sole binding properties of CNF in particleboard (PB) panels [59]. Modulus of rupture (MOR), modulus of elasticity (MOE), internal bond (IB), water absorption (WA), and thickness swelling (TS) properties were tested with varying amounts of CNF binder. With increased density levels, the MOR, MOE of the produced panels increased. With the increase in density of the panels the WA decreased but increase in the TS of the panels was observed in work. A recent study on improving the adhesive performance of ecofriendly cottonseed protein-based wood adhesives, CNF, and CNC at varying concentrations was investigated by Cheng et al. [60]. With $2 \%$ addition of CNF showed $22 \%$ improvement in dry adhesive strength, while for $\mathrm{CNC} 10 \%$ concentration improved adhesive performance by about $16 \%$. Addition of CNF showed the hot water resistance, but the improvement was observed in adhesive with CNC. Investigations were done on reinforcing effect of lingo-cellulose nanofiber (LCNF) in fiberboards made from softwood and hardwood fiber [61]. Compared with the control fiberboard, IB for LCNF-mixed fiberboard was higher. The TS and weight change (WC) with WA for fiberboards containing LCNF were lower than those for control fiberboards. Due to the binding between LCNF and wood fibers, addition of LCNF enhanced physical and mechanical properties of fiberboards, especially for softwood fiberboards. A recent study on gap-filling properties of lignin-containing CNF (LCNF) on polymeric diphenylmethane diisocyanate (pMDI) as a wood adhesive was investigated [62]. With small amount of LCNF into pMDI, enhancements in dry strength and wet strength in the lap-shear tests were shown. The formation of 
urethane linkages by Fourier transform infrared (FTIR) spectroscopy result shows the reaction of hydroxyl groups in LCNF with isocyanate groups in pMDI. Morphology of cured adhesives shows good dispersion of nano-sized fibrils. Improved the adhesive gap-filling properties shown by the inclusion of LCNF help in the formation of a continuous bond line.

Addition of CNF to Polyvinyl Acetate (PVAc)-starch adhesives was evaluated [47]. CNF in this study were made by nano fibrillation of dicarboxylic acid cellulose. With the addition of CNF increase in the lap-joint strength by $6.5 \%$ to $74.5 \%$ were estimated and the highest bond strength at $0.96 \%$ CNF. Performance of the adhesive failed at lower and higher concentrations of CNF. López-Suevos et al. investigated PVAc latex wood adhesive with increasing contents of the different types of nanofibrils [35]. CNF for the study were refined beech pulp (RBP), mechanically disintegrated RBP (MD-RBP), chemically modified RBP (CM-RBP) and chemical modified followed by mechanical disintegrated RBP (CM-MD-RBP). By mixing commercial PVAc latex with different concentrations of the untreated or the processed RBP fibrils resulting nanocomposite was prepared and dynamic mechanical analysis (DMA) was done for studying viscoelastic properties and fibril/PVAc interactions. High reinforcement in the high-temperature region was shown by carboxymethylated and subsequently mechanically disintegrated CNFs. Superior heat resistance with durability was observed on CM-RBP reinforced PVAc adhesives even though they performed worse in dry and wet conditions. To investigate the change in performance of PVAc wood adhesives by incorporation of Nanocrystalline cellulose (NCC), a study was conducted by Kaboorani et al. [34]. The bonding strength of wood joints and mechanical, thermal properties were studied with $1 \%, 2 \%$ and $3 \%$ of NCC. The morphological study by atomic force microscopy (AFM) showed poor dispersion and aggregation on PVAc matrix. Increasing concentration of NCC improved hardness, thermal stability, modulus of elasticity (MOE) and creep of PVAc films. Incorporation also improved the bonding strength of PVAc showed by block shear tests in all conditions such as dry and wet conditions also at the elevated temperature $\left(100^{\circ} \mathrm{C}\right)$. Wood adhesive formulated based on soybean meal showed enhancement in the performance by the addition of cellulose nano-whiskers $(\mathrm{CNW})$ [63]. The formulation used sodium hydroxide $(\mathrm{NaOH})$, and polyethylene glycol (PEG) as ingredients. Enhancement in water-resistance of a plywood specimen by $20 \%$ was observed by incorporating CNW in the adhesive. Morphological studies, by scanning electron microscopy (SEM), on cured adhesive incorporated with CNW, showed smooth surface with few holes and cracks which helped in improving the water-resistance of the adhesive meeting the interior plywood requirement.

Increase in viscosity was shown as the concentration of cellulose nanocrystals (NCC) to urea-formaldehyde (UF) adhesive increased for sugarcane bagasse particle boards [64]. The adhesive dispersion in the particleboard was prevented as NCC loading reached $5 \%$ due to the increase in viscosity. NCC forms hydro- 
gen bonding during the polymerization of UF adhesive and makes the chains stiff, hence contributes to increase in viscosity of the system. Sample with $1 \%$ NCC showed better mechanical performance with increase in the liquid suspension viscosity. The study showed the mechanism of UF adhesive polymerization and the possible interaction of NCC with UF resin, shown in Figure 2.

\section{Nanocellulose-PVA Crosslinking}

Effects on various properties by reinforcing Poly(vinyl alcohol) (PVA) hydrogels with varying concentration of cellulose nanocrystals (CNC) and crosslinking the system with glutaraldehyde were studied by Tanpichai et al. [65]. The cross-linker, glutaraldehyde was added in acidic condition to the CNC-PVA suspension for the reaction to initiate and a blank sample without $\mathrm{CNC}$ was also prepared with PVA and glutaraldehyde. The crosslinking reaction of glutaraldehyde with nanocellulose (NC) - PVA is shown in Figure 3. Thermal stability, swelling ratio and mechanical, and viscoelastic properties of cross-linked CNC-PVA hydrogels were investigated in the study. Increase in compressive strength of $303 \%$ with $1 \mathrm{wt} \%$ addition of CNCs at $60 \%$ strain compared to neat hydrogels was observed. Strain recovery after the removal of the load on CNC

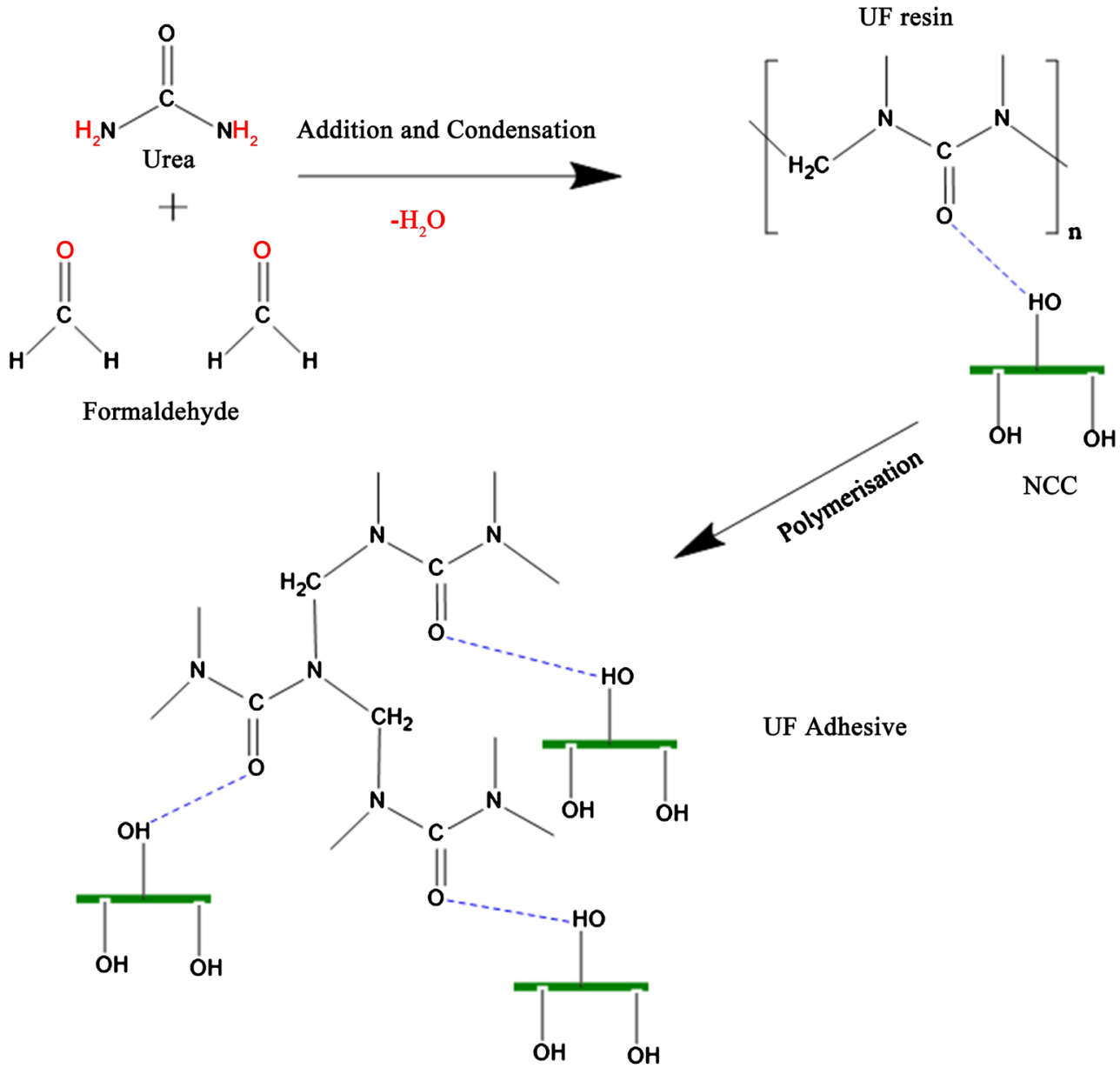

Figure 2. The mechanism of UF adhesive polymerization and interaction with NCC. 


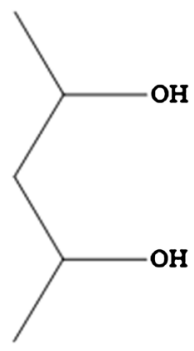

PVA

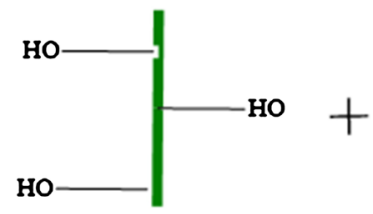

NC

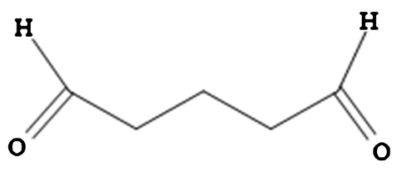

Glutaraldehyde

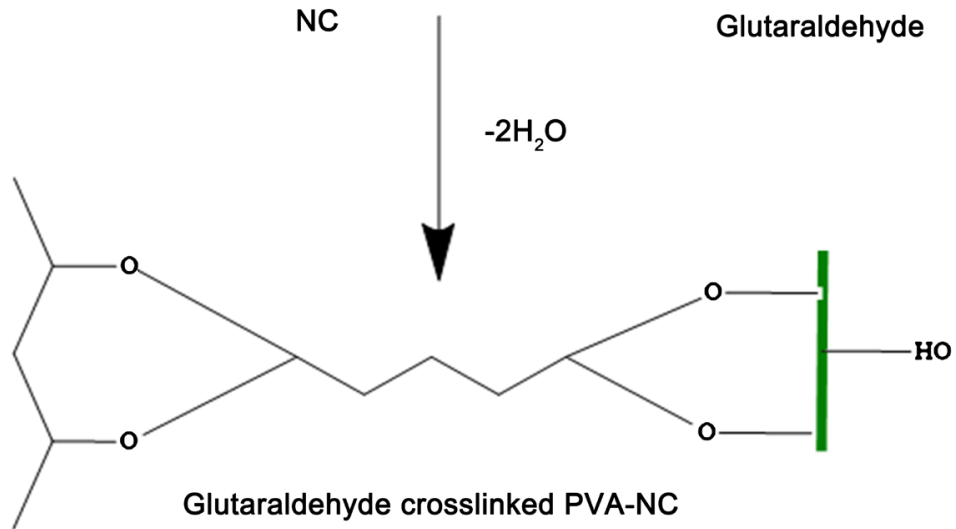

Figure 3. Crosslinking glutaraldehyde with poly vinyl alcohol (PVA) and nanocellulose $(\mathrm{NC})$.

added hydrogel was $97 \%$ while the crosslinked sample without CNC showed only $92 \%$ recovery. With the addition of CNCs the molecular chain restriction occurred and contributed to the decreased the creep elasticity. Improvements in the compressive stress, viscoelastic response and relaxation behavior with the addition of CNC on hydrogels were shown. The lower thermal stability of CNC contributed to decreasing in onset of degradation temperatures with increasing $\mathrm{CNC}$ content in crosslinked hydrogels. Decrease in the swelling ratio with increase in CNC content on crosslinked hydrogels was observed in the study.

From the same group, there is a study on mechanical and thermal properties of crosslinked poly (vinyl alcohol) composite films with cellulose nanocrystals [66]. Crosslinker for the system was sodium tetraborate decahydrate (borax), and different weight $\%$ of CNCs was added to the PVA matrix. For comparing and as a reference, the neat PVA films without borax and CNC were also prepared in the study. The possible reaction is shown in Figure 4. Crosslinked PVA-CNC films showed increase in glass transition temperature $(\mathrm{Tg})$ and decomposition temperature and mechanical properties while moisture uptake, melting temperature, and degree of crystallization decreased in comparison to neat PVA samples. Increase in crystallization temperature with the addition of CNCs in the crosslinked PVA nanocomposites was observed.

Acetal-bonding cross-linked polyvinyl alcohol (PVA) films were reinforced with different concentrations of cellulose nanocrystals(CNC) having carboxyl and aldehyde functionalities and its effects on mechanical, thermal, and barrier properties of the film were investigated by a study [67]. Carboxyl and aldehyde functionalities on $\mathrm{CNC}$ were given by mechanical treatment with partially 

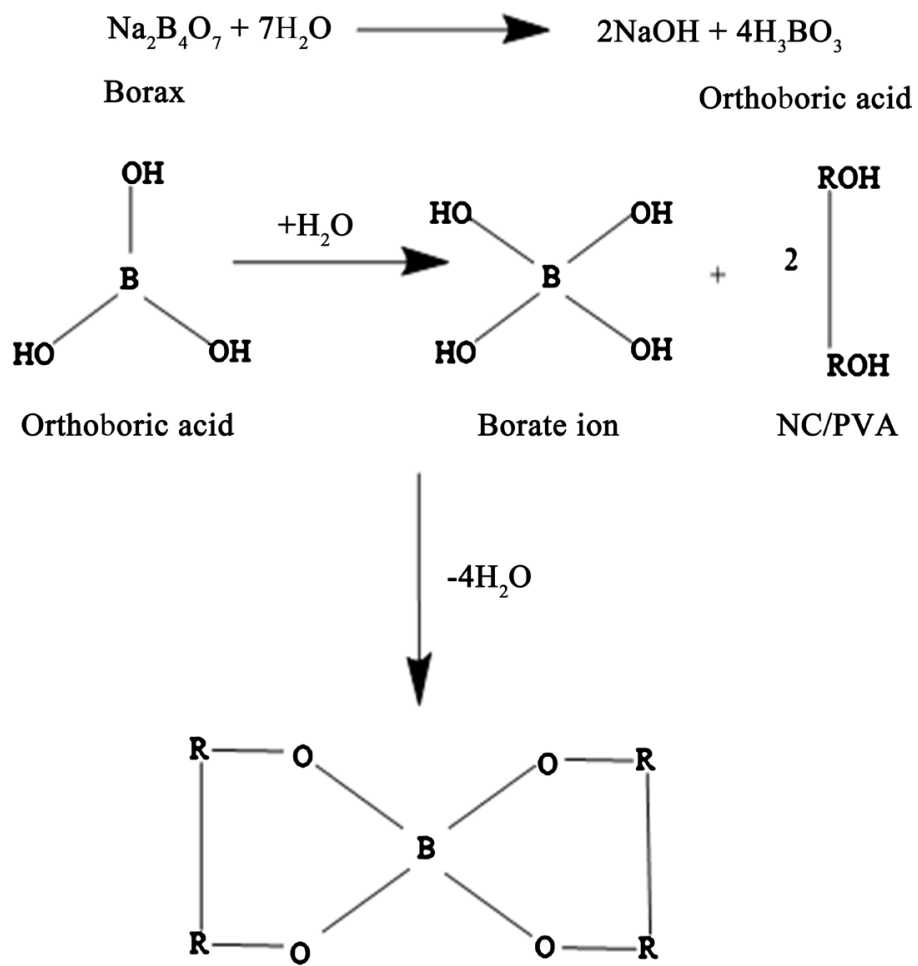

Cross-linked NC/PVA

Figure 4. Crosslinking reaction of nanocellulose (NC), Poly vinyl alcohol (PVA) with Borax.

carboxylated dialdehyde cellulose, and for the comparative study, $\mathrm{CNC}$ without reactive aldehydes was also prepared. Spoljaric et al. conducted a study in which nano fibrillated cellulose or cellulose nanofibers (CNF) based hydrogel physically blended with PVA and the system crosslinked with borax [68]. Increasing borax content increases the compact structure with enhancement in mechanical properties due to higher crosslink density. The reaction is shown in Figure 4. The effect of the addition of nanocellulose (both CNC and CNF) on PVA xerogels for biomedical applications was investigated by Pramanik et al. [69]. Hydrochloric acid was used as a catalyst and glutaraldehyde (GA) as a crosslinker for PVA-CNC, and PVA-CNF xerogels. By the addition of nanocellulose, creep strain and stress relaxation of the system reduced and thermal degradation observed at a lower temperature. A study on the reinforcement of cellulose nanocrystals (CNCs) prepared with formaldehyde as a crosslinking agent for PVA forms by Song, Tanpichai and Oksman [70]. With the introduction of CNCs to PVA, decrease in water uptake and an increase of the density were observed because of the reduction in pore size.

\section{Conclusion}

Introduction of nanocellulose in wood adhesives shows enhancement in both mechanical properties of adhesives and also improvements in performance properties. To further enhance the properties establishment of chemical bonds 
in the adhesive system is a must. Crosslinking of nanocellulose is one such approach which significantly improves various properties. The advantage with the crosslinking of nanocellulose is to facilitate the interconnected network formation without any phase separation and to provide synergetic property of the adhesive and nanocellulose in the wood adhesive system. Hence enhancement of various properties such as improved water resistance, enhanced film formation, and enhancement of thermal property with crosslinking could be advantageous in wood adhesives. Glutaraldehyde crosslinked nanocellulose showed formation of compact structure with decrease in creep elasticity and lower water uptake, and swelling ratio, and enhancement of mechanical properties. Borax crosslinked nanocellulose showed increase in glass transition temperature $(\mathrm{Tg})$ and decomposition temperature and mechanical properties. Studies reported in the incorporation of nanocellulose materials (NCC and CNF) with various adhesive system show enhancement of mechanical properties, and performance properties of adhesives even with the incorporation of minimal quantities of these nanomaterials. Since it is established the feasibility of modification of nanocellulose and its advantages, mainly two aspects need to be further studied. First is the need to find the mechanism of nanocellulose modification in wood adhesive system even though nanocellulose does not phase separates in the adhesive nanocomposite. Second is to optimize the crosslinking of nanocellulose with the help of various crosslinkers such as borax and aldehyde with adhesive system so to make it work as a functional nanofiller additive. Hence by these fundamental investigations, effective addition of bio-based functional nanofiller can be one of the competitors for conventional petroleum-based material, thereby reducing the dependency of petrochemicals in wood adhesive field.

\section{Conflicts of Interest}

The authors declare no conflicts of interest regarding the publication of this paper.

\section{References}

[1] He, Z., Zhang, Y. and Wei, W. (2012) Formaldehyde and VOC Emissions at Different Manufacturing Stages of Wood-Based Panels. Building and Environment, 47, 197-204. https://doi.org/10.1016/j.buildenv.2011.07.023

[2] Böhm, M., Salem, M.Z.M. and Srba, J. (2012) Formaldehyde Emission Monitoring from a Variety of Solid Wood, Plywood, Blockboard and Flooring Products Manufactured for Building and Furnishing Materials. Journal of Hazardous Materials, 221-222, 68-79. https://doi.org/10.1016/j.jhazmat.2012.04.013

[3] Roffael, E. (2006) Volatile Organic Compounds and Formaldehyde in Nature, Wood and Wood Based Panels. Holz als Roh und Werkstoff, 64, 144-149. https://doi.org/10.1007/s00107-005-0061-0

[4] Navarrete, P., et al. (2012) Low Formaldehyde Emitting Biobased Wood Adhesives Manufactured from Mixtures of Tannin and Glyoxylated Lignin. Journal of Adhesion Science and Technology, 26, 1667-1684.

[5] Hemmilä, V., Adamopoulos, S., Karlsson, O. and Kumar, A. (2017) Development of 
Sustainable Bio-Adhesives for Engineered Wood Panels-A Review. RSC Advances, 7, 38604-38630. https://doi.org/10.1039/C7RA06598A

[6] Syed, L.C., Imam, H., Gordon, S.H. and Mao, L.J. (2001) Environmentally Friendly Wood Adhesive from a Renewable Plant Polymer: Characteristics and Optimization. Polymer Degradation and Stability, 1, 40-44.

[7] Jang, Y., Huang, J. and Li, K. (2011) A New Formaldehyde-Free Wood Adhesive from Renewable Materials. International Journal of Adhesion and Adhesives, 31, 754-759. https://doi.org/10.1016/j.ijadhadh.2011.07.003

[8] Fatemeh Ferdosian, B.Z., Pan, Z.H. and Gao, G.H. (2017) Bio-Based Adhesives and Evaluation for Wood Composites Application. Polymers (Basel), 9, 70-99.

https://doi.org/10.3390/polym9020070

[9] Gadhave, R.V., Mahanwar, P.A. and Gadekar, P.T. (2017) Starch-Based Adhesives for Wood/Wood Composite Bonding: Review. Open Journal of Polymer Chemistry, 7, 19-32. https://doi.org/10.4236/ojpchem.2017.72002

[10] Gu, Y., Cheng, L., Gu, Z., Hong, Y., Li, Z. and Li, C. (2019) Preparation, Characterization and Properties of Starch-Based Adhesive for Wood-Based Panels. International Journal of Biological Macromolecules, 134, 247-254.

https://doi.org/10.1016/j.ijbiomac.2019.04.088

[11] Jiang, Y., Chen, Q., Tan, H., Gu, J. and Zhang, Y. (2019) A Low-Cost, Formaldehyde-Free, and High-Performance Starch-Based Wood Adhesive. BioResources, 14, 1405-1418.

[12] Wang, Z., et al. (2019) Improvement of the Bonding Properties of Cassava Starch-Based Wood Adhesives by Using Different Types of Acrylic Ester. International Journal of Biological Macromolecules, 126, 603-611. https://doi.org/10.1016/j.ijbiomac.2018.12.113

[13] Wang, Z., Li, Z., Gu, Z., Hong, Y. and Cheng, L. (2012) Preparation, Characterization and Properties of Starch-Based Wood Adhesive. Carbohydrate Polymers, 88, 699-706. https://doi.org/10.1016/j.carbpol.2012.01.023

[14] Gadhave, R.V., Srivastava, S., Mahanwar, P.A. and Gadekar, P.T. (2019) Lignin: Renewable Raw Material for Adhesive. Open Journal of Polymer Chemistry, 9, 27-38. https://doi.org/10.4236/ojpchem.2019.92003

[15] Yang, Z., Peng, H., Wang, W. and Liu, T. (2010) Lignin-Based Polycondensation Resins for Wood Adhesives. Journal of Applied Polymer Science, 116, 2658-2667.

[16] Khan, M.A., Ashraf, S.M. and Malhotra, V.P. (2004) Development and Characterization of a Wood Adhesive Using Bagasse Lignin. International Journal of Adhesion and Adhesives, 24, 485-493. https://doi.org/10.1016/j.ijadhadh.2004.01.003

[17] Moubarik, A., Grimi, N., Boussetta, N. and Pizzi, A. (2013) Isolation and Characterization of Lignin from Moroccan Sugar Cane Bagasse: Production of Lignin-Phenol-Formaldehyde Wood Adhesive. Industrial Crops and Products, 45, 296-302. https://doi.org/10.1016/j.indcrop.2012.12.040

[18] Hussin, M.H., et al. (2017) Preparation of Environmental Friendly Phenol-Formaldehyde Wood Adhesive Modified with Kenaf Lignin. Beni-Suef University Journal of Basic and Applied Sciences, 6, 409-418. https://doi.org/10.1016/j.bjbas.2017.06.004

[19] Kalami, S., Chen, N., Borazjani, H. and Nejad, M. (2018) Comparative Analysis of Different Lignins as Phenol Replacement in Phenolic Adhesive Formulations. Industrial Crops and Products, 125, 520-528. https://doi.org/10.1016/j.indcrop.2018.09.037

[20] Sulaiman, N.S., Hashim, R., Sulaiman, O., Nasir, M., Amini, M.H.M. and Hiziroglu, 
S. (2018) Partial Replacement of Urea-Formaldehyde with Modified Oil Palm Starch Based Adhesive to Fabricate Particleboard. International Journal of Adhesion and Adhesives, 84, 1-8. https://doi.org/10.1016/j.ijadhadh.2018.02.002

[21] Lei, H., Du, G., Wu, Z., Xi, X. and Dong, Z. (2014) Cross-Linked Soy-Based Wood Adhesives for Plywood. International Journal of Adhesion and Adhesives, 50, 199-203. https://doi.org/10.1016/j.ijadhadh.2014.01.026

[22] Buddi, T., Muttil, N., Nageswara Rao, B. and Singh, S.K. (2015) Development of a Soya Based Adhesive in Plywood Manufacturing. Materials Today: Proceedings, 2, 3027-3031. https://doi.org/10.1016/j.matpr.2015.07.289

[23] Vnučec, D., Kutnar, A. and Goršek, A. (2017) Soy-Based Adhesives for Wood-Bonding: A Review. Journal of Adhesion Science and Technology, 31, 910-931. https://doi.org/10.1080/01694243.2016.1237278

[24] Luo, J., Luo, J., Bai, Y., Gao, Q. and Li, J. (2016) A High Performance Soy Protein-Based Bio-Adhesive Enhanced with a Melamine/Epichlorohydrin Prepolymer and Its Application on Plywood. RSC Advances, 6, 67669-67676. https://doi.org/10.1039/C6RA15597A

[25] Mo, X. and Sun, X.S. (2013) Soy Proteins as Plywood Adhesives: Formulation and Characterization. Journal of Adhesion Science and Technology, 27, 2014-2026. https://doi.org/10.1080/01694243.2012.696916

[26] Khan, I. and Poh, B.T. (2011) Natural Rubber-Based Pressure-Sensitive Adhesives: A Review. Journal of Polymers and the Environment, 19, 793-811. https://doi.org/10.1007/s10924-011-0299-z

[27] Radabutra, S., Khemthong, P., Saengsuwan, S. and Sangya, S. (2019) Preparation and Characterization of Natural Rubber Bio-Based Wood Adhesive: Effect of Total Solid Content, Viscosity, and Storage Time. Polymer Bulletin, 1-11. https://doi.org/10.1007/s00289-019-02881-1

[28] Thuraisingam, J., Mishra, P., Gupta, A., Soubam, T. and Piah, B.M. (2019) Novel Natural Rubber Latex/Lignin-Based Bio-Adhesive: Synthesis and Its Application on Medium Density Fiber-Board. Iranian Polymer Journal, 28, 283-290. https://doi.org/10.1007/s13726-019-00696-5

[29] John, N. and Joseph, R. (1997) Studies on Wood-to-Wood Bonding Adhesives Based on Natural Rubber Latex. Journal of Adhesion Science and Technology, 11, 225-232. https://doi.org/10.1163/156856197X00327

[30] David, N.H. (1989) Chapter 21 Cellulosic Adhesives. In: Richard, S.J.B., Hemingway, W. and Conner, A.H., Eds., Adhesives from Renewable Resources, ACS Symposium Series, American Chemical Society, Washington DC, 289-304. https://doi.org/10.1021/bk-1989-0385.ch021

[31] Zhang, X.J. and Young, R.A. (2000) Adhesion Properties of Cellulose Films. MRS Online Proceeding Library Archive, 586, 157. https://doi.org/10.1557/PROC-586-157

[32] Zhao, B.X., Wang, P., Zheng, T., Chen, C.Y. and Shu, J. (2006) Preparation and Adsorption Performance of a Cellulosic-Adsorbent Resin for Copper (II). Journal of Applied Polymer Science, 99, 2951-2956. https://doi.org/10.1002/app.22986

[33] Veigel, S., Müller, U., Keckes, J., Obersriebnig, M. and Gindl-Altmutter, W. (2011) Cellulose Nanofibrils as Filler for Adhesives: Effect on Specific Fracture Energy of Solid Wood-Adhesive Bonds. Cellulose, 18, 1227-1237. https://doi.org/10.1007/s10570-011-9576-1

[34] Kaboorani, A., Riedl, B., Blanchet, P., Fellin, M., Hosseinaei, O. and Wang, S. (2012) Nanocrystalline Cellulose (NCC): A Renewable Nano-Material for Polyvinyl Ace- 
tate (PVA) Adhesive. European Polymer Journal, 48, 1829-1837. https://doi.org/10.1016/j.eurpolymj.2012.08.008

[35] López-Suevos, F., Eyholzer, C., Bordeanu, N. and Richter, K. (2010) DMA Analysis and Wood Bonding of PVAc Latex Reinforced with Cellulose Nanofibrils. Cellulose, 17, 387-398. https://doi.org/10.1007/s10570-010-9396-8

[36] Ayrilmis, N., Kwon, J.H., Lee, S.H., Han, T.H. and Park, C.W. (2016) Microfibrillated-Cellulose-Modified Urea-Formaldehyde Adhesives with Different F/U Molar Ratios for Wood-Based Composites. Journal of Adhesion Science and Technology, 30, 2032-2043. https://doi.org/10.1080/01694243.2016.1175246

[37] Kojima, Y., et al. (2014) Evaluation of Binding Effects in Wood Flour Board Containing Ligno-Cellulose Nanofibers. Materials (BaseI), 6, 6853-6864.

https://doi.org/10.3390/ma7096853

[38] Cataldi, A., Berglund, L., Deflorian, F. and Pegoretti, A. (2015) A Comparison between Micro- and Nanocellulose-Filled Composite Adhesives for Oil Paintings Restoration. Nanocomposites, 1, 195-203. https://doi.org/10.1080/20550324.2015.1117239

[39] Mahrdt, E., Pinkl, S., Schmidberger, C., van Herwijnen, H.W.G., Veigel, S. and Gindl-Altmutter, W. (2016) Effect of Addition of Microfibrillated Cellulose to UreaFormaldehyde on Selected Adhesive Characteristics and Distribution in Particle Board. Cellulose, 23, 571-580. https://doi.org/10.1007/s10570-015-0818-5

[40] George, J. and Sabapathi, S.N. (2015) Cellulose Nanocrystals: Synthesis, Functional Properties, and Applications. Nanotechnology, Science and Applications, 8, 45-54. https://doi.org/10.2147/NSA.S64386

[41] Moon, R.J., Martini, A., Nairn, J., Simonsen, J. and Youngblood, J. (2011) Cellulose Nanomaterials Review: Structure, Properties and Nanocomposites. Chemical Society Reviews, 40, 3941-3994. https://doi.org/10.1039/c0cs00108b

[42] Ferreira, F.V., Mariano, M., Rabelo, S.C., Gouveia, R.F. and Lona, L.M.F. (2018) Isolation and Surface Modification of Cellulose Nanocrystals from Sugarcane Bagasse Waste: From a Micro- to a Nano-Scale View. Applied Surface Science, 436, 1113-1122. https://doi.org/10.1016/j.apsusc.2017.12.137

[43] Grishkewich, N., Mohammed, N., Tang, J. and Tam, K.C. (2017) Recent Advances in the Application of Cellulose Nanocrystals. Current Opinion in Colloid \& Interface Science, 29, 32-45. https://doi.org/10.1016/j.cocis.2017.01.005

[44] Habibi, Y. (2014) Key Advances in the Chemical Modification of Nanocelluloses. Chemical Society Reviews, 43, 1519-1542. https://doi.org/10.1039/C3CS60204D

[45] Hamed, S.A.A.K.M. and Hassan, M.L. (2019) A New Mixture of Hydroxypropyl Cellulose and Nanocellulose for Wood Consolidation. Journal of Cultural Heritage, 35, 140-144. https://doi.org/10.1016/j.culher.2018.07.001

[46] Lengowski, E.C., Bonfatti Júnior, E.A., Nishidate Kumode, M.M., Carneiro, M.E. and Satyanarayana, K.G. (2019) Nanocellulose-Reinforced Adhesives for Wood-Based Panels. In: Inamuddin, Thomas, S., Kumar Mishra, R. and Asiri, A.M., Eds., Sustainable Polymer Composites and Nanocomposites, No. 167, Springer, Berlin, 1001-1025. https://doi.org/10.1007/978-3-030-05399-4_35

[47] Jiang, W., Haapala, A., Tomppo, L., Pakarinen, T., Sirviö, J.A. and Liimatainen, H. (2018) Effect of Cellulose Nanofibrils on the Bond Strength of Polyvinyl Acetate and Starch Adhesives for Wood. BioResources, 13, 2283-2292. https://doi.org/10.15376/biores.13.2.2283-2292

[48] Veigel, S., Rathke, J., Weigl, M. and Gindl-Altmutter, W. (2012) Particle Board and Oriented Strand Board Prepared with Nanocellulose-Reinforced Adhesive. Journal 
of Nanomaterials, 2012, Article ID: 158503. https://doi.org/10.1155/2012/158503

[49] Gadhave, R.V, Sheety, P., Mahanwar, P.A., Gadekar, P.T. and Desai, B.J. (2019) Silane Modification of Starch-Based Wood Adhesive: Review. Open Journal of Polymer Chemistry, 9, 53-62. https://doi.org/10.4236/ojpchem.2019.93005

[50] Desai, S.D., Patel, J.V. and Sinha, V.K. (2003) Polyurethane Adhesive System from Biomaterial-Based Polyol for Bonding Wood. International Journal of Adhesion and Adhesives, 23, 393-399. https://doi.org/10.1016/S0143-7496(03)00070-8

[51] Zheng, P., Li, Y., Li, F., Ou, Y., Lin, Q. and Chen, N. (2017) Development of Defatted Soy Flour-Based Adhesives by Acid Hydrolysis of Carbohydrates. Polymers (Basel), 9, 153. https://doi.org/10.3390/polym9050153

[52] Liu, D., Chen, H., Chang, P. R., Wu, Q., Li, K. and Guan, L. (2010) Biomimetic Soy Protein Nanocomposites with Calcium Carbonate Crystalline Arrays for Use as Wood Adhesive. Bioresource Technology, 101, 6235-6241. https://doi.org/10.1016/j.biortech.2010.02.107

[53] Kajtna, J. and Šebenik, U. (2017) Novel Acrylic/Nanocellulose Microsphere with Improved Adhesive Properties. International Journal of Adhesion and Adhesives, 74, 100-106. https://doi.org/10.1016/j.ijadhadh.2016.11.013

[54] Dastjerdi, Z., Cranston, E.D. and Dubé, M.A. (2018) Pressure Sensitive Adhesive Property Modification Using Cellulose Nanocrystals. International Journal of Adhesion and Adhesives, 81, 36-42. https://doi.org/10.1016/j.ijadhadh.2017.11.009

[55] Tayeb, A.H., Amini, E., Ghasemi, S. and Tajvidi, M. (2018) Cellulose Nanomaterials-Binding Properties and Applications: A Review. Molecules, 23, 1-24. https://doi.org/10.3390/molecules23102684

[56] Cai, Z. and Niska, K.O. (2012) Nanocelluloses: Potential Materials for Advanced Forest Products: Proceedings of Nanotechnology in Wood Composites Symposium.

[57] Kojima, Y., et al. (2013) Binding Effect of Cellulose Nanofibers in Wood Flour Board. Journal of Wood Science, 59, 396-401. https://doi.org/10.1007/s10086-013-1348-0

[58] Cui, J., et al. (2015) Enhancement of Mechanical Strength of Particleboard Using Environmentally Friendly Pine (Pinus pinaster L.) Tannin Adhesives with Cellulose Nanofibers. Annals of Forest Science, 72, 27-32. https://doi.org/10.1007/s13595-014-0392-2

[59] Amini, E., Tajvidi, M., Gardner, D.J. and Bousfield, D.W. (2017) Utilization of Cellulose Nanofibrils as a Binder for Particleboard Manufacture. BioResources, 12, 4093-4110. https://doi.org/10.15376/biores.12.2.4093-4110

[60] Cheng, H.N., Kilgore, K., Ford, C., Fortier, C., Dowd, M.K. and He, Z. (2019) Cottonseed Protein-Based Wood Adhesive Reinforced with Nanocellulose. Journal of Adhesion Science and Technology, 33, 1357-1368. https://doi.org/10.1080/01694243.2019.1596650

[61] Kojima, Y., et al. (2016) Reinforcement of Fiberboard Containing Lingo-Cellulose Nanofiber Made from Wood Fibers. Journal of Wood Science, 62, 518-525. https://doi.org/10.1007/s10086-016-1582-3

[62] Chen, H., Nair, S.S., Chauhan, P. and Yan, N. (2019) Lignin Containing Cellulose Nanofibril Application in pMDI Wood Adhesives for Drastically Improved Gap-Filling Properties with Robust Bondline Interfaces. Chemical Engineering Journal, 360, 393-401. https://doi.org/10.1016/j.cej.2018.11.222

[63] Gao, Q., Li, J., Shi, S.Q., Liang, K. and Zhang, X. (2012) Soybean Meal-Based Adhesive Reinforced with Cellulose Nano-Whiskers. BioResources, 7, 5622-5633. 
https://doi.org/10.15376/biores.7.4.5622-5633

[64] Mesquita, R.G.A., et al. (2018) Urea Formaldehyde and Cellulose Nanocrystals Adhesive: Studies Applied to Sugarcane Bagasse Particleboards. Journal of Polymers and the Environment, 26, 3040-3050. https://doi.org/10.1007/s10924-018-1189-4

[65] Tanpichai, S. and Oksman, K. (2016) Cross-Linked Nanocomposite Hydrogels Based on Cellulose Nanocrystals and PVA: Mechanical Properties and Creep Recovery. Composites Part A, 88, 226-233. https://doi.org/10.1016/j.compositesa.2016.06.002

[66] Tanpichai, S. and Oksman, K. (2018) Crosslinked Poly(vinyl alcohol) Composite Films with Cellulose Nanocrystals: Mechanical and Thermal Properties. Journal of Applied Polymer Science, 135, Article ID: 45710. https://doi.org/10.1002/app.45710

[67] Sirviö, J.A., Honkaniemi, S., Visanko, M. and Liimatainen, H. (2015) Composite Films of Poly(vinyl alcohol) and Bifunctional Cross-Linking Cellulose Nanocrystals. ACS Applied Materials \& Interfaces, 7, 19691-19699. https://doi.org/10.1021/acsami.5b04879

[68] Spoljaric, S., Salminen, A., Luong, N.D. and Seppälä, J. (2014) Stable, Self-Healing Hydrogels from Nanofibrillated Cellulose, Poly(vinyl alcohol) and Borax via Reversible Crosslinking. European Polymer Journal, 56, 105-117.

https://doi.org/10.1016/j.eurpolymj.2014.03.009

[69] Pramanik, R., Ganivada, B., Ram, F., Shanmuganathan, K. and Arockiarajan, A. (2019) Influence of Nanocellulose on Mechanics and Morphology of Polyvinyl Alcohol Xerogels. The Journal of the Mechanical Behavior of Biomedical Materials, 90, 275-283. https://doi.org/10.1016/j.jmbbm.2018.10.024

[70] Song, T., Tanpichai, S. and Oksman, K. (2016) Cross-Linked Polyvinyl Alcohol (PVA) Foams Reinforced with Cellulose Nanocrystals (CNCs). Cellulose, 23, 1925-1938. https://doi.org/10.1007/s10570-016-0925-y 